\title{
Um breve panorama sobre a Península Itálica na Baixa Idade Média, a partir do caso específico da cidade de Florença
} An brief overview of the Italian Peninsula in the Lower Middle Ages, from the specific case of the city of Florence

Thatiane Piazza de Melo ${ }^{1}$

\footnotetext{
${ }^{1}$ Doutoranda em História pela Universidade Federal Fluminense, tendo mestrado e graduação pela mesma. Orientadora: Renata Rodrigues Vereza. E-mail: thatianepiazza@hotmail.com.

Recebido em 11 de janeiro de 2021; Aceito em 3 de junho de 2021.
}

DOI: $10.12957 /$ nearco.2021.57047

\section{Resumo}

O artigo aborda sobre as relações políticas vivenciadas na Península Itálica na Baixa Idade Média, em específico sobre a cidade de Florença. Esta encontra-se cercada por distintos poderes que se opõem entre o Império Papal e o Sacro Império. Além disso, neste período também ocorreu a Guerra dos Cem Anos, que apesar de não serem conflitos ocorridos nesse território, trouxeram diversos impactos políticos. Depois também ocorreram diversos surtos da Peste Negra e apesar de tudo esses acontecimentos, esse período vivenciou também uma expansão dessa cidade.

Palavras-Chave: Península Itálica, Florença, Idade Média.

\begin{abstract}
The article deals with the political relations experienced in the Italian Peninsula in the Low Middle Ages, specifically about the city of Florence. This one is surrounded by different powers that oppose between the Papal Empire and the Holy Empire. In addition, during this period there was also the Hundred Years War, which, despite not being conflicts in that territory, brought several political impacts. Then there were also several outbreaks of the Black Death and despite all these events, that period also experienced an expansion of that city.
\end{abstract}

Keywords: Italic Peninsula, Florence, Middle Ages. 


\section{Introdução}

A Península Itálica, no período da Baixa Idade Média, abrangia uma região com uma grande diversidade política. Esse território era dividido em três principais e distintas áreas: as regiões norte, central e sul. Nesta última parte estavam localizados os reinos de Nápoles e da Sicília, ambos dominados politicamente pela casa de Anjou no século XIII. Porém, em 1282, o reino da Sicília passou ao poderio da casa aragonesa com o rei Pedro III, o Grande. Observa-se que essa região da Península conviveu, nesse período, com uma disputa entre os reinos de Aragão e da França, um contexto muito diverso do que foi vivenciado nas outras regiões.

A parte central tinha a cidade de maior influência: Roma, principalmente por seu poderio em decorrência do governo Papal que englobava diversos locais sob sua dominação. As cidades mais próximas a ela pertenciam a esse governo e eram denominadas de cidades pontifícias, incentivadas com construções católicas que fortaleciam esses vínculos de dominação. Até mesmo as cidades localizadas mais ao norte da Península Itálica vivenciavam essa disputa do poderio do Império Papal.

Por último, a região norte, abordada com maior intensidade nessa tese, era submetida aos grandes: ao Papa e ao Imperador do Sacro Império e, em alguns casos, a ambos ao mesmo tempo, tendo como um dos principais fatores, a sua localização, como mostra o mapa a seguir (Figura 1). (GUENÉE, 1981). Com relação ao poderio do Sacro Império na região norte da Península, o autor relatou que em 1282 as burguesias de Florença e de Siena só prestariam o juramento de fidelidade ao imperador caso ele aparecesse em pessoa, ou, ao menos, que uma tropa fosse enviada como sua representante. Nesse caso, o imperador Carlos IV esteve nas duas cidades e concedeu cargos políticos às mesmas, no intuito de legitimar o seu poder. Esse autor também descreve que esse poder foi garantido a partir do cargo de "vicariato de Império", ou seja, o imperador criava um alto cargo para instituir seu poder na região.

A Igreja Católica, na figura do papado também adotava esse tipo de estratégia nas cidades concedendo cargos e títulos. A nobreza e a alta burguesia citadina almejavam receber esses cargos tanto os concedidos pelo Papa, como pelo Imperador - 
vicariato papal e vicariato imperial, respectivamente - ou também um título senhorial conde, duque ou marquês - com a finalidade de obter maior controle sobre a população urbana. Outra estratégia instituída pelo Império Papal era o incentivo para as diversas construções religiosas nas cidades, edificações essas que também faziam parte de sua rede de controle desses locais.

No decorrer do século XIV, os imperadores perderam cada vez mais o seu poder na região norte da Península; os que ainda desempenharam relativa influência nesse local foram os imperadores Henrique VII e depois Carlos IV, contudo Frederico III não conseguiu ser coroado rei em Milão no ano de 1452.

No início do século XIV, e há muito tempo, o problema do Império divide os habitantes da península em dois partidos violentamente opostos. Os guelfos são os inimigos do imperador; os gibelinos são os seus amigos fiéis. $\mathrm{Na}$ verdade, desde esse momento", o divórcio entre as duas posições não é tão fundamental, pois os guelfos não recusam radicalmente a instituição imperial, assim como os gibelinos não condenam totalmente as liberdades comunais. Porém, no século XIV, guelfos e gibelinos vão aos poucos aproximando as suas perspectivas. E todos logo pensam que a sua política deve tender, antes de tudo, a salvaguardar a sua autonomia contra quem quer que seja. E todos admitem também que o imperador ainda tem uma função a desempenhar na península. Na realidade, está fora de dúvida que o Imperador intervém na vida política italiana no fim da Idade Média. (GUENÉE, 1981, p.57). 


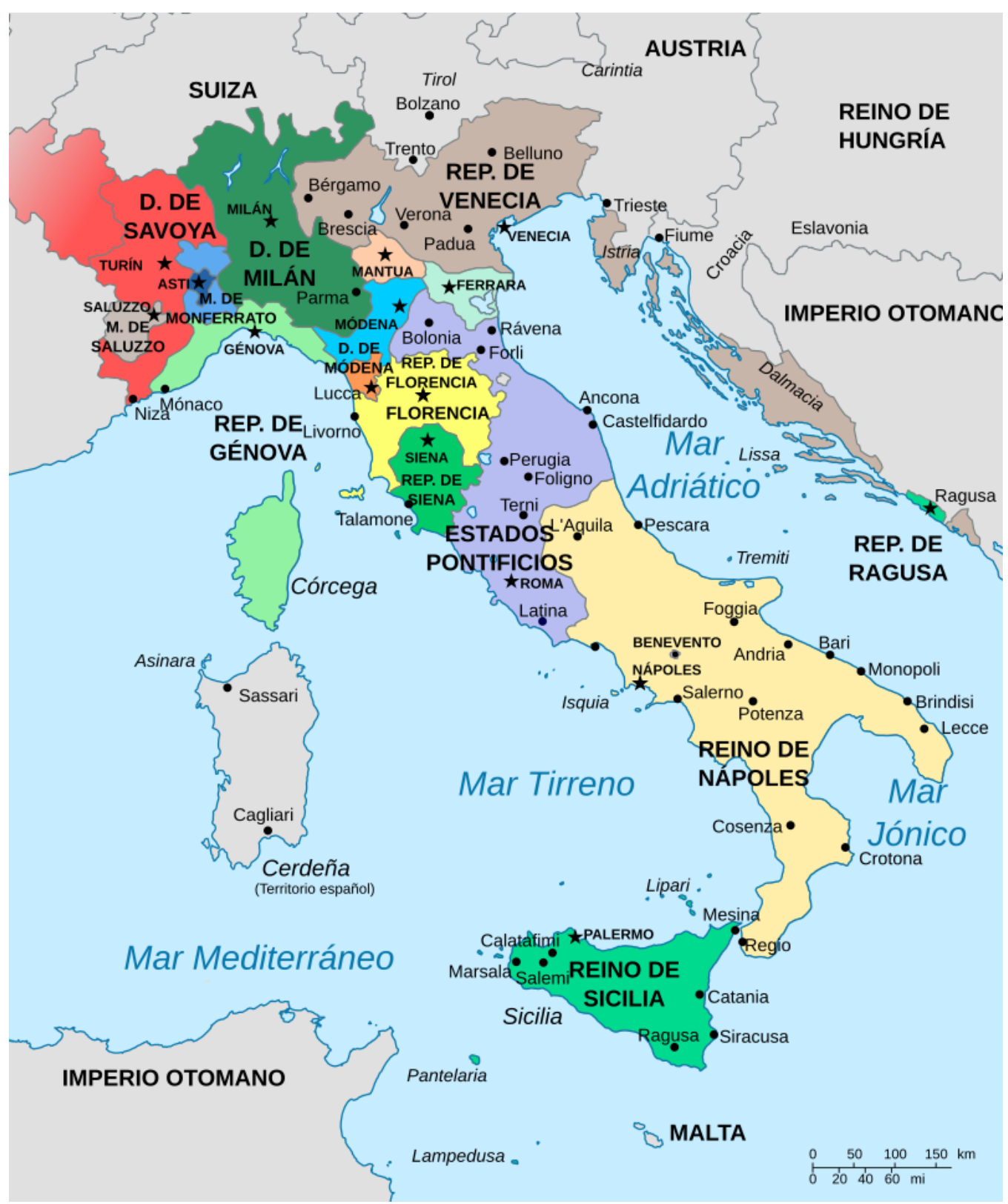

Figura 1 - Mapa da Península Itálica em 1494.

Referência: Disponível em:

https://pt.wikipedia.org/wiki/Hist\%C3\%B3ria_da_It\%C3\%A1lia\#/media/Ficheiro:Italia_1494-es.svg Acesso em: 07 de dez. 2020. 


\section{Contexto político}

Neste contexto também ocorreram conflitos armados que causaram um impacto social na região como, por exemplo, a Guerra dos Cem Anos entre os anos de 1337 até 1453. Uma guerra que envolvia diversos territórios na Europa, inclusive, indiretamente, a Península Itálica, uma vez que seus bancos auxiliavam a Inglaterra no financiamento desta. Com a derrota do rei Eduardo III da Inglaterra, não foi efetuado o pagamento das dívidas contraídas, levando alguns bancos italianos à falência. Assim, outras companhias com funções bancárias também sofreram esse destino, gerando um período conturbado economicamente.

Em meio à fragilidade econômica causada pela guerra, a região enfrentou também uma queda demográfica. Uma mudança climática que acarretou uma fase de clima mais frio e instável, entre 1315-1317, teve como consequência uma diminuição na produção de cereais, o que gerou um aumento no preço desses grãos. Esse fato incidiu substancialmente a população mais pobre que não possuía poder aquisitivo para comprar esses alimentos. Nota-se, portanto, um período de fome e fragilidade para essa parcela da população.

O declínio na taxa populacional era notado antes mesmo da própria Peste Negra devido à existência de longos períodos de fome. (PERROY, 1965). Em função desse panorama, foi rápida a contaminação gerada pela peste, já que uma população debilitada era mais vulnerável à contração de doenças. As pessoas que adoeciam eram, em sua maioria, pertencentes à parte mais pobre da população, mas ambos os setores sociais estavam apreensivos pela falta de conhecimento para combater este mal. (DELUMEAU, 1989).

Nota-se que as condições de salubridade das cidades favoreciam a proliferação de ratos, por conta das construções das moradias em condições precárias e pela sujeira dos dejetos que eram jogados nas ruas, devido à falta de saneamento básico no período. (LIDBERG, 2001). A Peste Negra em Florença teve seus primeiros surtos entre 1340-1341 e apresenta os piores momentos em: 1360-1363, 1371-1374, 1399-1400, 1417 e 14221425. Entre 1348 e depois em 1363, atingiu a cidade e reduziu consideravelmente a 
população. Se antes da peste a população da cidade chegava a possuir 90 a $100 \mathrm{mil}$ habitantes, depois desse episódio não passava de 60 mil pessoas. (TENENTI, 1973).

Nesse período, a Peste Negra se propagou rapidamente por toda a Europa e teve maior intensidade nas grandes cidades portuárias, sendo a mortalidade mais alta entre os grupos mais pobres. (FRUGONI e BARBERO, 1999). Já para as famílias ricas, os autores atribuem a menor mortalidade não tanto pela alimentação, mas pela possibilidade de fugirem para o campo ou para lugares em que quase não existia a doença, como o caso dos jovens florentinos que fogem da cidade de Florença durante uma crise de Peste Negra relatado no livro "Decamerão". (BOCCACCIO, 1803). A diminuição da população causada pela Peste Negra provocou uma mudança considerável nas cidades italianas. Esse panorama levou a falência de algumas companhias mercantis que se depararam com a falta de mercadorias e de clientes para os seus produtos. Essa elite de comerciantes das cidades portuárias, localizadas ao norte e ao centro da Península Itálica.

\section{Estudo de caso: Florença}

As origens dessa cidade são remetidas ao Império Romano. A cidade pertencia ao Império no ano de 59 a.C, período no qual governava Cesar Augusto. (NESTI, 2010). Era um pequeno espaço de território, um quadrilátero com aproximadamente 500 metros de lado e que era um acampamento romano, possuindo por volta de 37 hectares e uma população de mais de 10.000 pessoas. (NORMAN, 1995). Nesse período foi construída a primeiro muro em volta da cidade, erguido no final do I século a.C. Na metade do século III, São João Batista foi nomeado padroeiro da cidade em uma tentativa de dominação pela Igreja Católica, já que essa posição era anteriormente atribuída ao deus Marte, divindade pagã.

Com o fim do Império Romano, alguns povos de diferentes localidades dominaram a cidade na Idade Média. Primeiros os Bizantinos no século VI, depois os Lombardos nos séculos VII e VIII e, depois, os Francos no século IX, com o domínio do 
Império Carolíngio na cidade. Após a morte de Carlos Magno, o poderio do seu império foi diminuído, perdendo a influência na região da Península Itálica.

No decorrer das migrações germânicas ao longo da Alta Idade Média, a população nas cidades diminuiu e foram feitas fortificações no centro urbano de Florença. No século IX receberam muros construídos pelo governo da cidade, com os quais traziam a divisão entre as pessoas que estavam dentro e a grande parte da cidade que existia fora desses muros. No século $\mathrm{XI}$, a cidade tinha um papel ativo na política da Península com uma população que cresceu consideravelmente e chegou a aproximadamente 20.000 habitantes. (NORMAN, 1995).

Neste mesmo século, a cidade de Florença apoiava o papa Gregorio VII e a condessa Matilda com o grupo dos guelfos, que eram aliados ao Pontífice, e que queriam manter Florença como uma comuna independente. Já o grupo dos gibelinos eram apoiadores do Imperador Henrique IV e tinham a ambição de retomada do Império Romano. O poder imperial entrou em conflito com o Império Papal que possuía sua centralidade em Roma. Contudo, de acordo com a sua posição geográfica, a cidade estava mais próxima de Roma, dessa forma a Igreja Católica conseguia exercer seu poderio de forma mais efetiva em Florença.

A cidade, no século XII, teve uma grande expansão comercial, econômica e demográfica, crescendo consideravelmente de tamanho. Nesse período Florença atinge aproximadamente 80 hectares e por volta de 30.000 pessoas moravam na cidade. (NORMAN, 1995). Um reflexo do crescimento pode ser observado entre 1173-74 no qual foram construídos novos muros em Florença que incorporaram este novo espaço urbano. O século XIII também foi marcado por um crescimento demográfico, com a migração de muitas pessoas dos arrabaldes para morar dentro da muralha, algumas pertencentes à própria região e outras oriundas de cidades vizinhas. (PINTO, 2016).

No início do século XIV, Florença manteve esse crescimento populacional e demográfico descrito no século XII. Para atender a tamanho crescimento, o espaço citadino sofreu alterações. Em 1284 foi projetada por Arnolfo di Cambio uma muralha que ampliava o território da cidade de Florença, construção que englobava os burgos da 
cidade e possuía 73 torres, em cada torre havendo duas portas. "Em 1333 foi terminada a última mura de Florença, permaneceu intacta até a segunda metade de 1800." (PETROLI, A, e PETROLI, F, 2017, p.14).

A Figura 2 a seguir, apresenta a planta da cidade nos Trezentos, com esta nova mura e as diversas construções arquitetônicas desenvolvidas nesse período. Foram construídos monumentos de destaque, como: a Catedral Santa Maria del Fiore, o Campanário, a Igreja de São Lourenço, a Igreja de Santa Croce, a Igreja Orsanmichele, a Igreja Santa Maria Novella, o Palácio Bargello e o Palácio Vecchio. Essas duas últimas construções eram as sedes de governo da cidade, nas quais os representantes também habitavam. Contudo, podemos destacar que todos os outros monumentos descritos são construções religiosas, principalmente igrejas, sendo tal aspecto ratificante do grande poder que o Império Papal exercia na cidade neste século. 


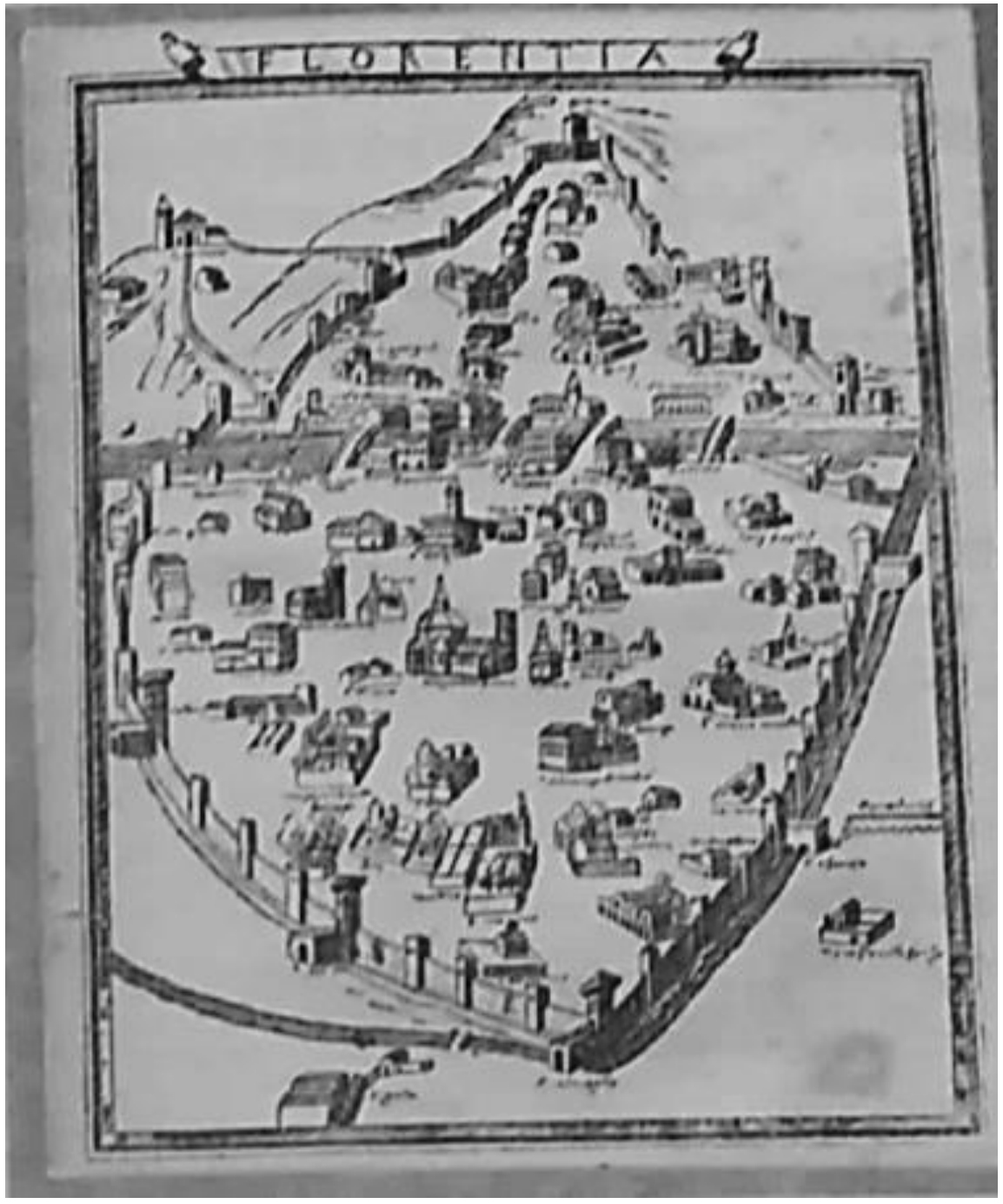

Figura 2 - Planta prospectiva de Florença. Século XIV.

Referência: PETRIOLI, Andrea e PETRIOLI, Fabrizio. 1333. Firenze dove passavano le ultime mura. Firenze: Edizioni Polistampa, 2017, p.15

\section{Considerações Finais}

Apesar da cidade de Florença ter vivenciado um período conturbado na Idade Média nos conflitos entre o Império Papal e o Sacro Império, além da Guerra dos Cem Anos e dos intensos surtos de Peste Negra, não se pode rotular esse período como a "idade das trevas", em contraposição ao anterior, que trouxe o crescimento e desenvolvimento das cidades como a "idade do ouro". Nota-se que esses dois termos 
dividiram a historiografia ao descreverem de forma antagônica um mesmo período: o medieval.

Todavia, a partir das questões apresentadas nesse artigo, torna-se claro que apesar desses conflitos vivenciados, nesse mesmo período da Baixa Idade Média em que a cidade se expande. Passando a receber novos muros e construções, Florença demonstra toda a sua riqueza e importância neste momento. Para além de uma visão apenas pessimista sobre esse período, é necessário demonstrar que ocorreram grandes transformações nas cidades que impulsionaram seu crescimento. Sendo assim, o intuito seria desmistificar tamanha visão, corroborando coma perspectiva de que esses dois momentos estiveram presentes nos diversos acontecimentos ao longo da Idade Média e configuram uma relação dual dessa sociedade. (LE GOFF, 2008).

\section{Referências Bibliográficas}

BARBERO, Alessandro e FRUGONI, Chiara. Medioevo: Storia di voce, racconto di immagini. Roma: Editori Laterza, 1999.

BOCCACCIO, Giovanni. Decameron. Milano: Società tipografica de Classici italiani, 1803.

DELUMEAU, Jean. Tipologia dos comportamentos coletivos em tempo de peste. In:___ . História do medo no Ocidente: 1300-1800, uma cidade sitiada. São Paulo: Companhia das Letras, 1989.

GUENÉE, Bernard. O Ocidente nos séculos XIV e XV: os Estados. São Paulo: Pioneira e Editora da Universidade de São Paulo, 1981

LE GOFF, Jacques. Uma Longa Idade Média. Rio de Janeiro: Civilização Brasileira, 2008.

LINDBERG, Carter. Crise agrária, fome coletiva e peste. In: . As Reformas na Europa. São Leopoldo: Sinodal, 2001. cap.2, pp. 38-72.

NESTI, Riccardo. As cidades de Arte: Florença, história da arte e folclore. Florença: ATS Italia Editrice, 2010.

NORMAN, Diana. Siena, Florence and Padua: art, Society and religion 1280-1400. London: Yale University Press, 1995, vol.2. 
PERROY, Édouard. A Idade Média. Rio de Janeiro: Difusão Europeia do Livro, 1965.

PETRIOLI, Andrea e PETRIOLI, Fabrizio. 1333 Firenze dove passavano le ultime mura. Firenze: Edizioni Polistampa, 2017, cit.p.14.

PINTO, Giuliano. Firenze medievale e dintorni. Roma: Viella, 2016.

TENENTI, Alberto. Florença na época dos Médici: da Cidade ao Estado. São Paulo: Perspectiva S.A, 1973. 